\title{
THE ROLE OF SERUM AND LOCAL IgE CONCENTRATION IN QUALITY OF LIFE IN ALLERGIC RHINOSINUSITS PATIENTS
}

\author{
A. Vlaykov ${ }^{1}$, D. Mihaylov ${ }^{1 *}$, V. Stoyanov ${ }^{1}$, M. Platikanova ${ }^{2}$ \\ ${ }^{1}$ Department of Otorhinolaryngology, Medical Faculty, Trakia University, Stara Zagora, Bulgaria \\ ${ }^{2}$ Department of Hygiene, Infectious Diseases and Epidemiology, Medical Faculty, Trakia University, \\ Stara Zagora, Bulgaria
}

\begin{abstract}
Purpose: The task we set was to determine the concentrations of IgE molecules in serum and nasal lavage in patients with intermittent and persistentallergic rhinitis (AR) and to compare them with a control group of healthy volunteers, comparing the results with a quality of life questionnaire about their subjective feeling of potential health damage.

Material and methods:: A comparison was performed between serum and nasal lavage $\operatorname{IgE}$ concentration in 50 participants - 40 cases and 10 controls.

Results: Serum level of IgE-total in the patients with intermittent (AR) was $284,19 \mathrm{IU} / \mathrm{ml}$ while in persistent (AR) patients - 215,29 IU/ml, but not significantly higher than in the controls $-160,87 \mathrm{IU} / \mathrm{ml}$. IgE antibodies in nasal lavage in IAR patients was $1,39 \mathrm{IU} / \mathrm{ml}$, while in PAR was $1,65 \mathrm{IU} / \mathrm{ml}$ and 1,05 $\mathrm{IU} / \mathrm{ml}$ in controls. Total score of SNOT-22 in IAR $(2,16)$ and PAR $(2,03)$ was significantly higher than in the controls $(0,85)$.

Conclusions:In our study, although the different serum levels of IgE among groups, we did not find significant correlation between the concentration of IgE antibodies in blood serum or nasal lavage and the degree of impairment of the quality of life in patients with IAR and PAR assessed by SNOT-22 quality of life test.
\end{abstract}

Key words: Allergic rhinitis, Chronic rhinosinusitis, Quality of life, SNOT-22, Immunoglobulin E

\section{INTRODUCTION}

Allergic rhinitis (AR), is a common hereditary airway disease, which represents an inflammation of the nasal cavity, caused by first type allergic reaction to a variety of allergens, mediated by IgE and characterised by nasal congestion and/nasal discharge ( nasal drip), sneezing and itching. Very often the inflammation affects paranasal sinuses and even trachea and bronchs (AR with allergic asthma). When inflammation affects both nasal cavity and paranasal sinuses, the diagnosis is rhinosinusitis (ARS). ARS is characterised by nasal congestion or nasal discharge (anterior/posterior nasal drip) facial pain/pressure, reduction or loss of smell. In

\footnotetext{
*Correspondence to: Dimitar Mihaylov, 11 Armeyska Str, 6000 Stara Zagora, Bulgaria, Phone: +359887532476, E-mail: dmihailov69@abv.bg
}

case symptoms persist for more than 12 weeks, the diagnosis is chronic rhinosinusitis (CRS). (1) All symptoms are combined with objective signs of disease, identified by CT scan, X-ray and rhinoscopy. There are 2 different types ofCRS, based on inflamation patterns:1.CRS with nasal polyposis (CRSwNP), 2.CRS without nasal polyposis (CRSsNP) (2)

Allergic rhinitis is typically triggered by seasonal allergens such as grass or tree pollen, and indoor allergens such as dust mites, mold, cockroaches, animal dander (fragments of fur or feathers).

Immunoglobulin E (IgE) has a key role in multiple airway diseases, including allergic rhinitis (AR) and chronic rhinosinusitis with nasal polyposis (CRSwNP). Allergic rhinitis is a clinical manifestation of a first type (Coombs $\&$ Gell) hypersensitivity reaction. For the 
VLAYKOV A., et al.

manifestation of the symptoms of the disease is required a complex of reactions, including components of the immune system - cells, mediators, cytokines, neuropeptides, adhesion molecules, etc (3). A key role in clinical manifestation of AR, have antibodies of class IgE (4). They have a molecular structure similar to other immunoglobulin classes, with two specific antigen binding sites, associated with the constant $(\mathrm{Fc})$ region. It is considered that in the blood serum they do not have substantial biological meaning and manifest their effect only when they are associated with blood basophils or tissue mast cells, where they have a role of a receptor for contact with the molecules of the allergen. In case of interaction, mediators released by these cells are the cause of the clinical manifestation of immediate-phase allergic reaction. (5)

Mast cells are important effector cells in the immediate-phase allergic reaction, as they can induce IgE synthesis once they produce Th2type cytokines like IL-4 and IL-J3. They also have a versatile role in allergic inflammation. IgE production can occur locally in the nasal mucosa. NMC interact with nasal epithelial cells, which contributes to the inflammatory process even more. (6).

These IgE values are generally low and specific IgE response to an allergen is often followed by a significant increase in their total serum concentrations (7). It is important to note that usual lower serum levels of IgE-total in healthy individuals do not exclude the presence of a greater amount of antigenspecific antibodies and development of a hypersensitivity response in a possible reaction with corresponding foreign molecules.

\section{MATERIALS AND METHODS}

All participants, after a detailed presentation of the purpose, objectives and methodology of the study and provided an opportunity for discussion, have signed an informed consent form.

Measurement of concentration of IgE-total was performed with IgE-Sandwich ELISA-kits. (Nova Tec Immunodiagnostica Gmbh). Statistical data processing was carried out using IBM SPSS Statistics v.21.0 / 2012. It was used standard SNOT-22 questionnaire for sinonasal pathology.

\section{RESULTS AND DISCUSSION}

Allergic rhinitis is characterized by a constellation of symptoms of the nose, eyes, ears, mouth and palate. Local symptoms include itching, sneezing, nasal congestion, rhinorrhea, cough and post nasal drip into the pharyngeal cavity. In combination with local symptoms, many patients with AR have systemic effects, such as headache, fatigue, sleep disturbances, loss of smell and cognitive impairment, most of them due to nasal obstruction.In many sinonasal diseases, IgE is crucial in the pathogenesis. Systemic markers to investigate inflammation in upper airway disease are sometimes not representative for local inflammation. Because IgE are unique to each allergen, checking for specific variants in blood or nasal secretion could be more sensitive than total $\operatorname{IgE}$ antibodies. $\operatorname{IgE}$ that is locally produced in the target organ could have diagnostic and therapeutic importance in AR and CRSwNP.

A comparison was performed between serum and nasal lavage IgE concentration in 50 participants - 40 cases and 10 healthy controls (21 males and 29 females) with mean age of $40,86 \pm 17,37$ (ranging from 19 to 79 ) years.

Serum level of IgE-total in the patients with intermittent allergic rhinitis was 284,19 IU/ml and in persistent allergic rhinitis patients 215,29 IU/ml, but not significantly higher than in the controls $-160,87 \mathrm{IU} / \mathrm{ml}$. However, level of serum IgE-total did not differ between the two allergic groups (Figure 1).

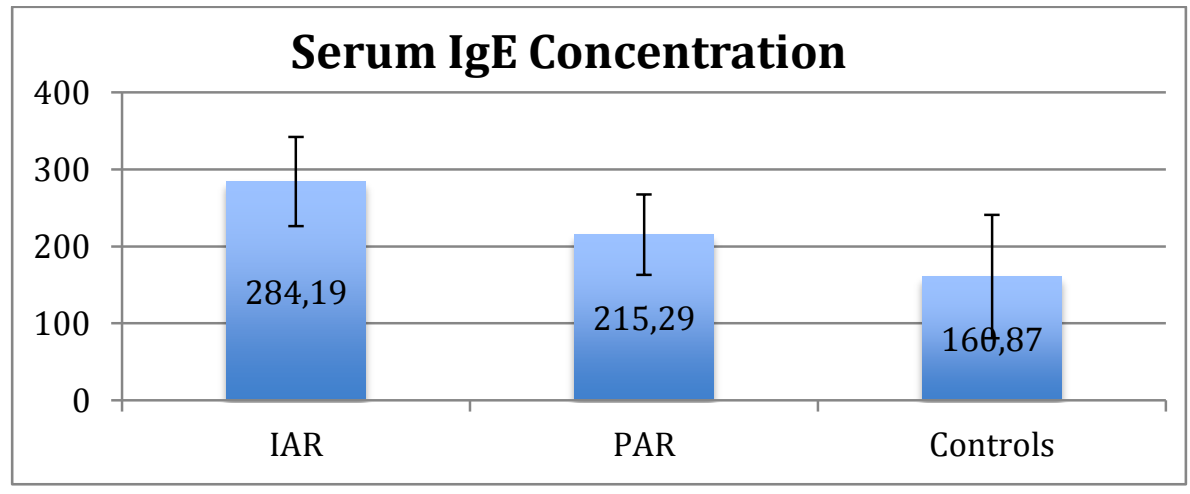

Figure 1. Blood serum IgE concentration in AR patients 
IgE antibodies in nasal lavage in IAR patients was $1,39 \mathrm{IU} / \mathrm{ml}$, while in PAR was $1,65 \mathrm{IU} / \mathrm{ml}$ and 1,05 IU/ml in controls (Figure 2).

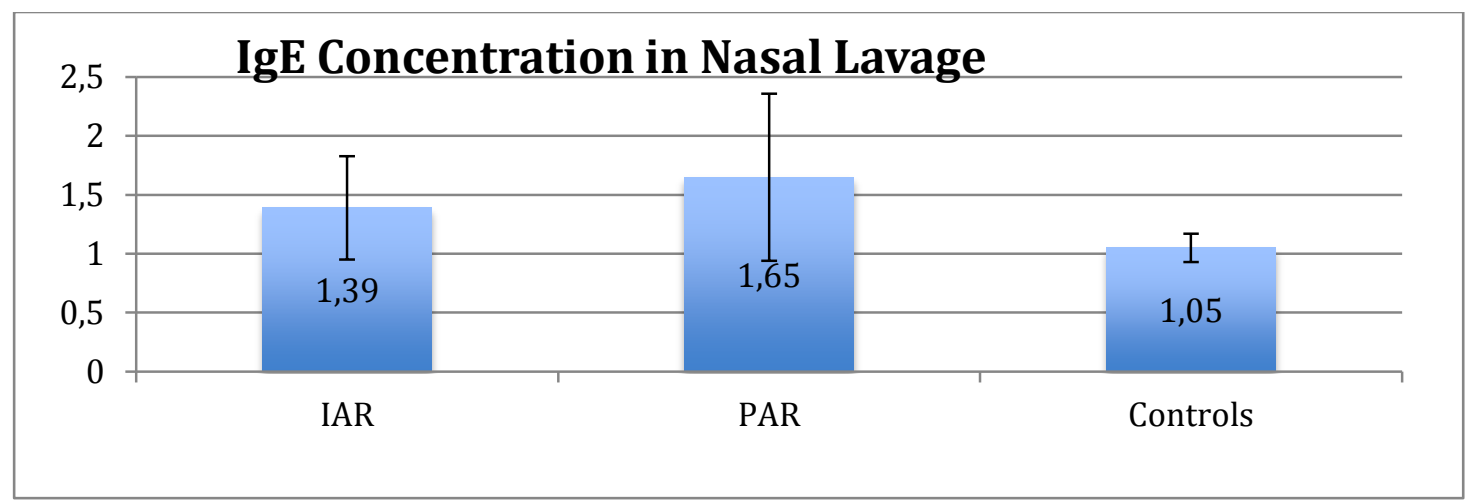

Figure 2. IgE concentration in nasal lavage in AR patients

Total score of SNOT-22 in IAR $(2,16)$ and PAR $(2,03)$ was significantly higher than in the controls 0,85 (Figure 3).

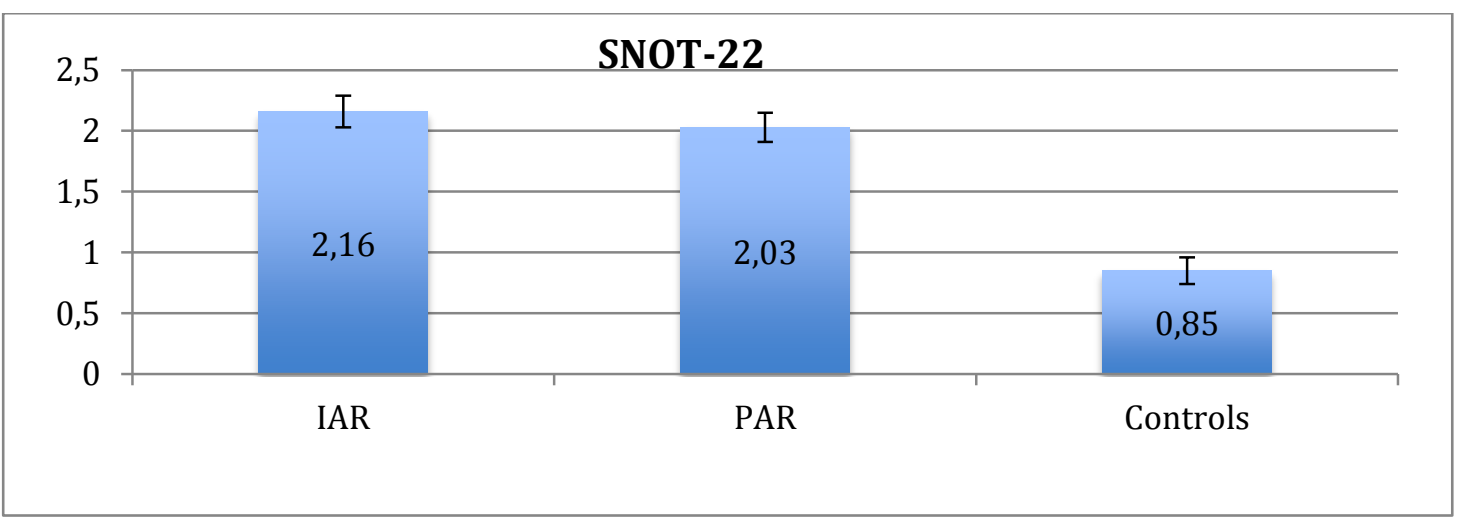

Figure 3. Total SNOT-22 score in AR patients

\section{CONCLUSIONS}

In our study, although the different serum levels of IgE among groups, we did not find significant correlation between the concentration of IgE antibodies in blood serum or nasal lavage and the degree of impairment of the quality of life in patients with intermittent and persistent allergic rhinitisassessed by SNOT-22 quality of life test.

\section{REFERENCES}

1. Hoffmans, R., Wagemakers, A., van Drunen, C., Hellings, P., Liu, Z.. Acute and chronic rhinosinusitis and allergic rhinitis in relation to comorbidity, ethnicity and environment, 13(2), 2018.

2. Hueston, K., Lalbry, R. et. al, Allergy in ENT Practice, $7^{\text {th }}$ Edition, New York, 8283, 2005.

3. Rondón, C., Campo, P., Togias, A., Fokkens, W., Durham, S., Powe, D. et al. Local allergic rhinitis: Concept, pathophysiology, and management. $J$ Allergy Clin Immunol.129(6):1460-7, 2012.

4. Howarth, PW. Allergic and non allergic rhinitis. In: Adkinson F Jr, Yunginger JW, Busse WW, Bochner BS, Holgate ST, Simons ER, Eds. Middleton's Allergy Principles and Practice. Mosby, Pennsylvania; 1391-1414,2003.

5. Pawankar, R., Yamagishi, S., Yagi, T. Revisiting the Roles of Mast Cells in Allergic Rhinitis and its Relation to Local IgE Synthesis. American Journal of Rhinology \& Allergy. 14 (5):309-318, 2000.

6. Tharwat, E. Deraz Immunopathogenesis of allergicrhinitis. Egypt J Pediatr. AllergyImmunol, 8(1):3-7, 2010.

7. Dykewicz, M., Fineman, S. Diagnosis and management of rhinitis: complete guidelines of the Joint Task Force on Practice Parameters in Allergy, Asthma, and Immunology. Ann Allergy Asthma Immunol. (Pt II): 478-518,1988. 
VLAYKOV A., et al. 